\title{
Temperature and precipitation in Northeast China during the last 150 years: relationship to large-scale climatic variability
}

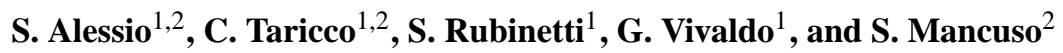 \\ ${ }^{1}$ Dipartimento di Fisica, Università di Torino, Torino, Italy \\ ${ }^{2}$ Osservatorio Astrofisico di Torino, INAF, Pino Torinese, Italy \\ Correspondence to: S. Alessio (alessio@ph.unito.it)
}

Received: 11 January 2014 - Revised: 15 May 2014 - Accepted: 16 May 2014 - Published: 2 July 2014

\begin{abstract}
The analysis of two historical time series of temperature and precipitation in Northeast China, spanning, respectively, 1870-2004 and 1841-2004, performed by continuous wavelet transform and other classical and advanced spectral methods, is presented here. Both variables show a particular trend and oscillations of about 85, 60, 35 and 20 years that are highly significant, with a phase opposition at the centennial scale and at the 20 -year scale. The analysis of the four temperature series relative to single seasons shows that the 20-year cycle is typical of the summer monsoon season, while the 35-year cycle is most evident in winter. The cycles of $\sim 60$ years and longer are present in all seasons. The centennial variation of temperature and precipitation describes well the 1970-1980 transition between a period of relatively strong East Asian Summer Monsoon (EASM), corresponding to high precipitation and relatively cool temperatures in Northeast China, and a conditions of weak EASM (low precipitation and warm temperatures). The connection of the detected local variations with large-scale climatic variability is deduced from the comparison with different climatic records (Northern Hemisphere temperature, Pacific Decadal Oscillation and Atlantic Multidecadal Oscillation indexes).
\end{abstract}

Keywords. Meteorology and atmospheric dynamics (climatology)

\section{Introduction}

The East Asian summer monsoon (EASM) strongly affects China's climate (Tao et al., 2004; Ding and Chan, 2005; Huang et al., 2012) and is forced by the effect of landsea thermal contrast, in which the elevated heat source represented by the huge massif of the Tibetan Plateau plays a key role. The northeasterly monsoon prevails in winter, the southwesterly monsoon in summer. The season with the most intense rainfall is summer. From September to April, the winter monsoon blows from the Siberian and Mongolian plateaus to the mainland of China, weakening gradually from northwest to northeast, and brings about a cold and dry climate, though with large spatial temperature differences. The duration of the wet summer monsoon is shorter, from April to September. The summer monsoon blows from the northwestern Pacific and Indian oceans, causing high temperature and abundant precipitation in China, with small differences in temperature from north to south.

According to Ding and Chan (2005) and Ding (2007), the general Asian-Pacific monsoon is divided into three subsystems: the Indian summer monsoon (ISM), the western North Pacific summer monsoon (WNPSM) and the EASM. The EASM region spans the belt $20-45^{\circ} \mathrm{N}, 110-140^{\circ} \mathrm{E}$ that covers eastern China, Korea, Japan and the adjacent marginal seas (Ding and Chan (2005), specify that this definition does not fully agree with the notion used by Chinese meteorologists, who usually include the South China Sea (SCS) in the EASM region). While the ISM and WNPSM are tropical monsoons in which the low-level winds reverse primarily from winter easterlies to summer westerlies, the EASM is a subtropical monsoon in which the low-level winds reverse primarily from winter northerlies to summer southerlies (Wang and Lin, 2002). This character of EASM implies intense influence from mid- and high-latitude phenomena. Primary contributing factors to the activity of EASM are the Pacific and Indian ocean surface temperatures and snow cover in the Eurasia and the Tibetan Plateau, as well as the variability of the atmospheric circulation (Ding and Chan, 
2005). The onset of the EASM is brought about by a positive feedback between the large-scale atmospheric circulation and mesoscale convective systems. The first breakout of the monsoon takes place over the SCS and Indochina; then the monsoon system migrates northward, so that the onset of summer rainfall in North China (NC) is delayed with respect to this primary breakout and the intensity of summer precipitation in NC depends on the intensity of the EASM: a strong monsoon, besides the impact of tropical cyclones, implies more precipitation in NC. More precisely, rainfall occurs mainly in front of the southwesterly winds maxima. This major rain belt associated with the monsoon is found in the Yangtze River (YR) basin in early summer and then moves to $\mathrm{NC}$ in middle summer. When the EASM circulation is strong, southwesterly winds are strong, so that they frequently reach into more northern regions; the rain belt thus travels to more northern areas, causing less rainfall in the YR basin and more rainfall in NC. Thus the multiannual and multidecadal variability of summer rainfall in the YR basin is usually the opposite of that in the northern parts of China (Zhao and Zhou, 2008).

In this paper, two historical time series of temperature and precipitation recorded in Northeast China (Beijing; $39^{\circ} 54^{\prime} 50^{\prime \prime} \mathrm{N}, 116^{\circ} 23^{\prime} 30^{\prime \prime} \mathrm{E}$ ) are studied and their significant modes of variation are extracted in order to single out possible connections with global climate variability patterns, with a focus on multidecadal timescales. The climate of Beijing is of the subhumid, continental monsoon type, being affected by EASM. The city is located at a relatively short distance from the sea but since it lies in a lowland area protected by mountains in the north and west and the prevailing air flow is from continental land during most of the year, maritime effects are limited, while local topographic effects are important. Winters are long, cold and dry; summers are hot, with torrential rains in late summer. The interannual precipitation variability is quite large.

The climate of China has been the subject of a great number of investigations in recent years. Qian et al. (2008) summarized several studies on climate variability in China on various timescales. We mention only a few of them here. Wang et al. $(1998,2000,2004)$ published climatic series over the last century (1880-2002); these consisted of an annual mean temperature anomaly series of 10 districts identified on the basis of their climatological characteristics and seasonal precipitation series over East China. Most of these data are observations, especially in East China. These data were used to analyze recent trends and multidecadal oscillations. It was found that - similarly to the temperature change of the Northern Hemisphere ( $\mathrm{NH}$ ) and of the world in the last 100 years - temperature in China exhibits an evidently increasing trend. A multidecadal variation ( $\sim 70$ years) and a $\sim 20$-year oscillation both in temperature and precipitation were also found (Qian et al., 2008). These oscillations are similar to those of the multidecadal and interdecadal variation in the global climate system (Mann and Park, 1994; Schlesinger and Ramankutty, 1994).

Oscillations on these timescales were also found in a series of reconstructed climatic variables over the last 5001000 years or more, the majority of which are temperature series, mostly derived from ice cores and tree rings in the west of China and from document records in the east (see, e.g., Yang et al., 2002; Ge et al., 2003, 2005; Wang et al., 2007). For example, Qian et al. (2003) inferred the existence of short-period oscillations (20 and 35 years) and long-period oscillations (70-80 years) in dryness-wetness for these three regions by forming a millennium-long dryness-wetness index series in the Yellow River basin, the lower YR basin and South China by these reconstructions and also examining the Seoul precipitation series (that is the longest historical climatic record of East Asia, starting from 1777). Qian et al. (2008), looking back to recent research about climate in China, especially on dryness and wetness changes, concluded that 20-30-year and 70-80-year oscillations in the EASM region can be considered as being well documented.

In agreement with these authors, Stige et al. (2007) and Zhang et al. (2009), in studies concerning the abundance of the oriental migratory locust Locusta migratoria manilensis (recorded in China for over 1000 years) in relation to temperature and precipitation reconstructions from 957-1956 AD, list oscillations of about 40- and 70-year-long periods, resulting from spectral analysis of temperature series, and an oscillation of an about 20-30-year-long period in precipitation. They also detect a longer, almost bicentennial variation in temperature.

Other recent studies, based on Asiatic local proxy records, detected quasi-periodical behavior. For example, Yang et al. (2006) examined temperature and precipitation oscillations over the past 1700 years recorded in an ice core taken from one of the thickest ice caps in central Asia, the Guliya ice cap $\left(35^{\circ} 17^{\prime} \mathrm{N}, 81^{\circ} 29^{\prime} \mathrm{E}\right)$. The temperature record was derived from $\delta^{18} \mathrm{O}$ measurements, while the precipitation series was deduced from ice accumulation. The results show temperature and precipitation oscillations with multiple timescales. Temperature data indicate the existence of intermittent oscillations with periods of approximately 40 and 70 years as well as longer. Precipitation data show significant periodicities at 20-30 and 60 years as well as on longer timescales.

Shen et al. (2009) used measurements of recent decades, 1500 -year-long proxy data and model simulations to study the temporal and spatial variability of summer precipitation over East China during the last millennium, with a focus on the middle and lower YR valley (MLYRV) and NC. On the interannual scale, 2-3-year and 5-7-year cycles, the typical TBO (tropospheric biennial oscillation) and ENSO (El NiñoSouthern Oscillation) signals, are well evident in observational data over the MLYRV and NC. Spectral analysis of the regional proxy data of summer precipitation allowed us to detect three statistically significant bidecadal (15-35 years), 
pentadecadal (40-60 years) and centennial (65-170 years) oscillation bands. A comparison of observational with modeled data suggested that the centennial oscillation could be linked to the secular variation of solar forcing (Gleissberg cycle), while the pentadecadal and bidecadal oscillations could be associated with internal variability of the climate system.

Hao et al. (2008), based on the series of precipitation in the middle and lower reaches of the Yellow River during 1736-2000, reconstructed with annual time resolution from the rainfall and snowfall archives of the Qing Dynasty (Zheng et al., 2005), investigated precipitation cycles and explored the possible climate forcings which drive precipitation changes. They found that precipitation has interannual and interdecadal oscillations of $2-4, \sim 20$ and $70-80$ years. The 2-4-year cycle was found to be connected to El Niño events. For the $\sim 22$-year and the 70-80-year precipitation cycles, Hao et al. (2008) found a relationship to the Wolf sunspot number. In particular, on the 70-80-year timescale they found a strong coincidence between solar activity variation and precipitation, with strong (weak) solar activity generally correlating to dry (wet) periods over the Yellow River region, but only before 1830 . After this date, they observed a lengthening of the solar secular cycle to $80-100$ years, while the precipitation cycle in their data remains $70-80$ years in length, so that the correspondence is lost. They attributed this to the possible disturbance to precipitation caused by increasing greenhouse gas concentration after 1830 . They also compared precipitation variations with a reconstruction of the Pacific Decadal Oscillation (PDO) index derived from tree rings in western North America and found a 20-30-year cycle active in both variables from 1736 to 1940 , but without a definite phase relationship between precipitation and PDO variations. The 70-80-year oscillations, present in precipitation and in the reconstructed PDO index during the whole record duration, were found to be opposite in phase.

Turning finally to the site of the records examined in the present analysis, precipitation in Beijing over the last three centuries (1724-2005) has been previously studied with annual resolution by Wei et al. (2008), who found $\sim 70-, \sim 30$ and $\sim 20$-year oscillations. Zhao et al. (2004) and Zhao and Han (2005), employing the wavelet transform, had previously detected nearly the same oscillations in the annual Beijing precipitation series (1749-2001) and had suggested a possible influence of solar activity on Beijing precipitation.

With these findings in mind, we analyzed the Beijing series of monthly mean air temperature and precipitation by several classical and advanced spectral methods, with the aim of extracting the main climatic oscillations at this site (Sect. 2). In Sect. 3 we place the results in the context of large-scale modes of climatic variability.

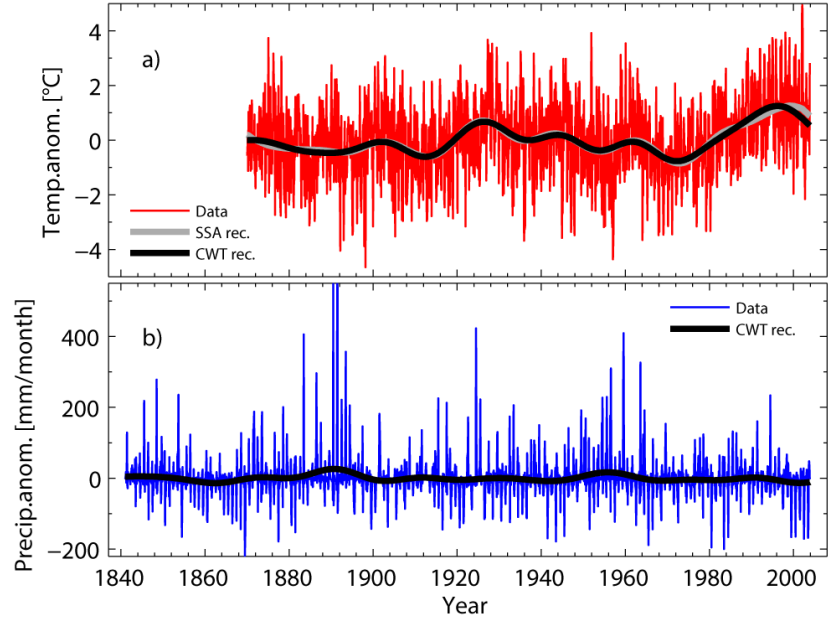

Figure 1. (a) Monthly mean temperature anomalies in Beijing (red line) and corresponding smoothed curves obtained by CWT reconstruction on the basis of periods $\geq 17$ years (black line; see text for details). Also shown is the SSA (singular spectrum analysis) reconstruction including all multidecadal components significant at the $99 \%$ confidence level (grey line). The window length used for SSA was $M=600$, corresponding to 50 years. (b) Monthly precipitation anomaly series in Beijing (blue line) and corresponding smoothed curve (black line) obtained by CWT reconstruction on the basis of periods $\geq 17$ years

\section{The series and their spectral content}

The historical time series of mean air temperature recorded in Beijing with monthly resolution spans 134 years, from 1870 to 2004 . The time series of monthly precipitation rates covers 163 years, from 1841 to 2004. These data were kindly provided by Prof. Zeng QingCun (Institute of Atmospheric Physics - IAP, Chinese Academy of Sciences, Beijing).

Before performing spectral analysis, we removed the respective annual cycles from both series, by subtracting from each monthly sample the average value over the entire record of the corresponding calendar month. Figure 1a shows the series of monthly mean temperature anomalies obtained in this way; Fig. $1 \mathrm{~b}$ shows the series of monthly precipitation anomalies. The record lengths are $N=1608$ and $N=1956$, respectively.

Superimposed on the raw data in Fig. 1a and b, black lines show smoothed versions of each series that were obtained from continuous wavelet transform (CWT) analysis.

In this case the CWT is used as a lowpass filter: after computing the CWT coefficients, the series is reconstructed by inverse CWT (ICWT) using only a given range of scales (periods). Specifically, in the case of Fig. 1a and b, all periods $<17$ years were excluded in order to obtain the smooth black curves. The reason for this precise cutoff is explained later in this section. In the following discussion, these smoothed versions of temperature and precipitation anomalies will be referred to as "multidecadal and centennial" 
reconstructions. The correlation coefficient between these two reconstructions is -0.41 (significance $>99 \%$ with sample size equal to 131), indicating anticorrelation between temperature and precipitation in Beijing at multidecadal and centennial scales.

Temperature has a prominent maximum at the end of the 1920s. From 1900 to the end of the record we also notice an overall increase in temperature, apparently on the order of over $1{ }^{\circ} \mathrm{C}$.

It may be interesting to compare, first of all, the Beijing temperature series with other temperature series relative to East China. For this comparison, shown in Fig. 2, we choose two paleoclimatological reconstructions. The first, which will be referred to as the "East China" reconstruction, is taken from Ge et al. (2003) and concerns the central area of East China, a region including the middle and lower reaches of the Yellow and Yangtze rivers, whose basins are located south of Beijing. The considered region is quite large: it extends east of the $105^{\circ} \mathrm{E}$ meridian, between $\sim 27$ and $\sim 40^{\circ} \mathrm{N}$, and includes Beijing at its most northern edge. The series is a reconstruction of regionally averaged, winter half-year temperatures over the past 2000 years, as deduced from phenological cold/warm events recorded in Chinese historical documents. The time resolution varies from 10 to 30 years (10 years in the last centuries). The second series derives from a 2650-year-long speleothem record from Shihua Cave $\left(115^{\circ} 56^{\prime} \mathrm{E}, 39^{\circ} 47^{\prime} \mathrm{N}\right.$; $251 \mathrm{~m}$ above sea level at the entrance), located about $50 \mathrm{~km}$ southwest of downtown Beijing. Warm season temperatures with annual resolution were reconstructed on the basis of correlations between thickness variations in the annual layers of a stalagmite (Tan et al., 2003). In Fig. 2, Beijing annually averaged temperature is plotted on the right-hand axis (thin red line; annual data were obtained by grouping monthly temperatures from December to November of the following year). Superimposed onto raw data, their smoothed version is shown as a thick red line; it was obtained using the smoothing "adaptive" filter proposed by Mann (2004, 2008), a 10-point Butterworth lowpass filter applied in association with boundary constraints designed to minimize edge effects, here with a cutoff frequency of $1 / 17$ years $^{-1}$. It nearly coincides with the CWT-filtered multidecadal and centennial reconstruction from Beijing monthly temperature anomalies, drawn in black in Fig. 2 and also visible in Fig. 1a. Plotted on the same axis, red diamonds represent the East China reconstruction (Ge et al., 2003). On the left-hand axis, whose span is equal to the right-hand one, the Shihua Cave temperature record (Tan et al., 2003) is plotted as a thin green line, together with the corresponding smoothed version, obtained by applying the same filter (thick green line). From Fig. 2 it may be seen that the amplitude of temperature variations shown by the Beijing record is confirmed by the Ge et al. (2003) East China reconstruction. Concerning the comparison between the Beijing and Shihua Cave records, we notice a certain similarity of bidecadal oscillations at the two sites, although temperature

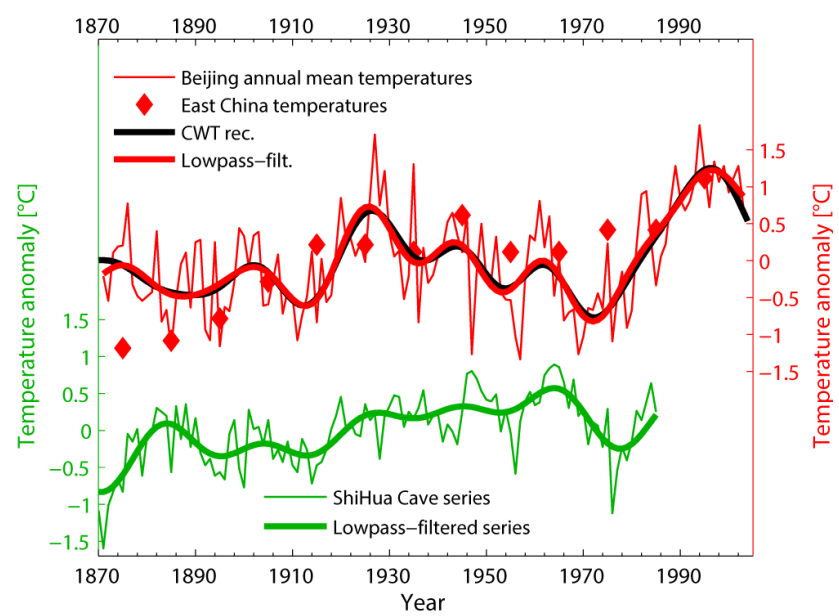

Figure 2. Beijing annual mean temperature anomaly (thin red line), its long-term behavior (heavy red line: from lowpass filtering with a cutoff frequency of $1 / 17$ years $^{-1}$; black line: from analogous CWT filtering; see text for details) and the East China (Ge et al., 2003) temperature reconstruction (red diamonds) plotted on the right-hand $y$ axis, compared to the Shihua Cave temperature record (Tan et al., 2003) plotted on the left-hand $y$ axis (thin green line: data; heavy green line: long-term behavior from lowpass filtering with a cutoff frequency of $1 / 17$ years $^{-1}$ ).

variations at Shihua Cave appear to be smaller than those in Beijing and the trends over the period 1920-1970 are not in agreement. The amplitudes of the modern temperature increases in Beijing and at Shihua Cave cannot be compared because the Shihua Cave temperature series ends in 1985.

In order to provide evidence of similarities and differences between local and hemispheric mean temperatures, we compare in Fig. 3 the annual temperature anomaly in Beijing (thin red line) and its smoothed version (heavy red line) with the $\mathrm{NH}$ annual mean temperature anomaly HadCRUT3 $^{1}$ record (Brohan et al., 2006) (anomaly: thin green line; smoothed version: heavy green line). The smooth curves were obtained by applying the filter by Mann (2008) with a cutoff frequency of $1 / 17$ years $^{-1}$. First we observe that the local temperature has fluctuations of greater amplitude than the hemispheric one, as may be expected. Moreover, both records exhibit a bidecadal oscillation and the modern rise

\footnotetext{
${ }^{1}$ HadCRUT is the dataset of monthly instrumental temperature records formed by combining the sea surface temperature records compiled by the Hadley Centre of the UK Met Office and the land surface air temperature records compiled by the Climatic Research Unit (CRU) of the University of East Anglia (UK). HadCRUT3 is a gridded data set of global historical surface temperature anomalies. We used annual average nearsurface temperature anomalies from 1850 to 2013 from the HadCRUT3 data set ("HadCRUT3 Diagnostics: Northern hemisphere average series - Annual series smoothed with a 21-point binomial filter", available at: http://hadobs.metoffice.com/hadcrut3/ diagnostics/hemispheric/northern/).
} 


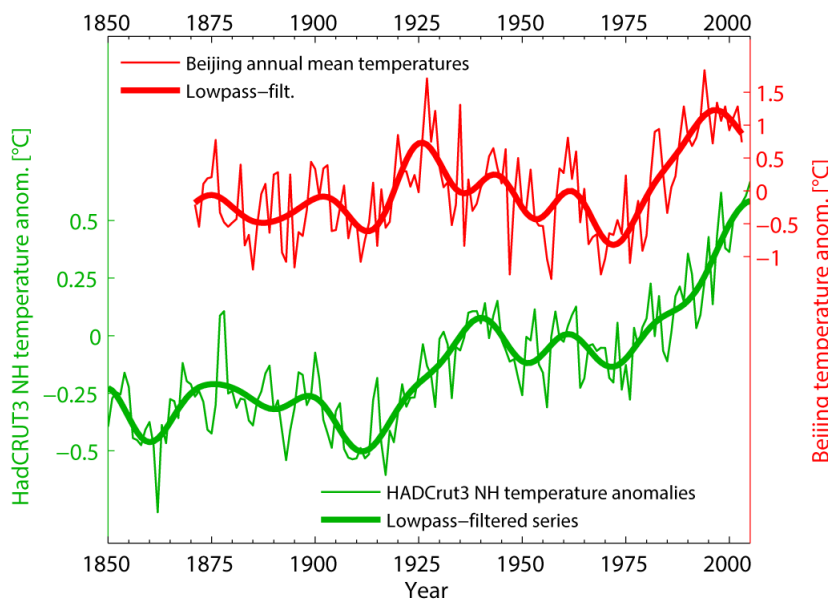

Figure 3. Beijing annual mean temperature anomaly (thin red line) and its long-term behavior (heavy red line) from lowpass filtering with a cutoff frequency of $1 / 17$ years $^{-1}$ (see text for details) plotted on the right-hand $y$ axis, compared to the HadCRUT3 record of Northern Hemisphere annual mean temperature anomaly plotted on the left-hand $y$ axis (thin green line: data; heavy green line: long-term behavior from lowpass filtering with a cutoff frequency of $1 / 17$ years $^{-1}$ ).

after 1970. This rise follows a temperature decrease that, however, starts in 1940 for the $\mathrm{NH}$, while it starts about 15 years before locally, when NH temperatures are increasing. These features suggest that multidecadal and centennial temperature fluctuations in Beijing are at least partly affected by large-scale processes, as already confirmed by Bradley et al. (1984).

The steep modern temperature increase in Beijing is well visible in Fig. 3 and appears, like all post-1940 variations, to have occurred nearly contemporaneously with the hemispheric one. The linear trend from 1979 to 2005 that the last IPCC Report (Solomon et al., 2007) quantifies in $0.33^{\circ} \mathrm{C} \mathrm{decade}^{-1}$ for $\mathrm{NH}$ land surfaces, appears as big as $\sim 0.8^{\circ} \mathrm{C} \mathrm{decade}^{-1}$ for Beijing during the 80 s and continues until the late $90 \mathrm{~s}$. It is then followed by a distinct decrease during the last 10-15 years of the record. It must be noted that the remarkable warming during the 80s and 90s may not only be related to natural variability and/or global anthropogenic causes, but also to local urbanization effects. Yan et al. (2010) estimated an overall urban-related warming bias in Beijing of about $0.3^{\circ} \mathrm{C} \mathrm{decade}^{-1}$, accounting for about $40 \%$ of the overall warming for the last three to four decades; this estimate was close to what Portman (1993) suggested for large cities in China. However, the general agreement between the local and hemispheric curves in Fig. 3 seems to exclude a local amplification of temperature variations during the last decades.

Since CWT is an evolutionary spectral method and its results are temporally local over a time interval comparable to the considered scale, we can assume that only the longest scales are somewhat influenced by the urban-related temperature increase during the last 20-30 years. This hypothesis was tested by repeating the CWT analysis excluding the interval after 1970, well before the start of the rapid Beijing urbanization. In spite of the shortness of the remaining record, the results were essentially confirmed.

Let us now turn to precipitation. It is evident from Fig. 1b that the multidecadal and centennial range of periods only explains a small part of the series variance: much highfrequency variability is present. Very wet periods around 1890 and in the decade of 1950-1960 emerge; in particular, a huge peak is present, corresponding to July 1891, in which $995.7 \mathrm{~mm}$ of rain were recorded. The decade of 1900-1940 appears as a relatively dry interval, as well as the ante- 1880 and the post-1970 intervals. The JJA summer-monsoonrelated precipitation, which was $483.5 \mathrm{~mm} \mathrm{season}^{-1}$ on average before 1970 , dropped by over $200 \mathrm{~mm} \mathrm{season}^{-1}$ in recent decades. Summer monsoon precipitation and summer temperature in Beijing are anticorrelated: the Pearson correlation coefficient between summer temperature and precipitation is -0.29 , which is significant at the $95 \%$ confidence level (hereafter c.1.). The correlation coefficient becomes -0.42 , significant at the $99 \%$ c.l., if the two series are smoothed by a smoothing Mann adaptive filter with a cutoff frequency of $1 / 17$ years $^{-1}$.

The Beijing monthly anomaly series were analyzed by applying classical and advanced spectral methods: stationary methods such as Fourier spectra, autoregressive (AR) spectra, multi-taper method (MTM), wavelet transform (WT) and singular spectrum analysis (SSA). Here, we will mainly focus on the results obtained by continuous wavelet transform (Foufoula-Georgiou and Kumar, 1994; Percival and Walden, 2000; Torrence and Compo, 1998).

The wavelet transform allows an evolutionary spectral analysis of a series on the timescale plane (Foufoula-Georgiou and Kumar, 1994; Percival and Walden, 2000; Torrence and Compo, 1998). A complex Morlet wavelet (cmor) with parameter $\omega_{0}=6$ was employed as a mother wavelet. For this wavelet, the scale is nearly equal to the Fourier period. The CWT discretization was performed computing the transform at each time step and on a dense set of scales. Scales were chosen as integer and fractional powers of 2; a total of 421 scales extending over 10.5 octaves was considered, with 40 intervals in each octave. The minimum scale is $2 T_{c}=2(1 / 12) \simeq 0.17$ years, while the maximum one corresponds to a period $\simeq 250$ years that is the limit beyond which the spectral power tends to 0 for both variables. The calculations were performed by a set of Matlab scripts and functions based on the wavelet software made freely available by C. Torrence and G. P. Compo at http://paos.colorado.edu/research/wavelets/.

In Fig. 4, panels a and b, the scalograms of temperature and precipitation, expressing spectral density as a function of time and Fourier period, are shown by color-filled contour plots in the time-period plane. Black lines in the 

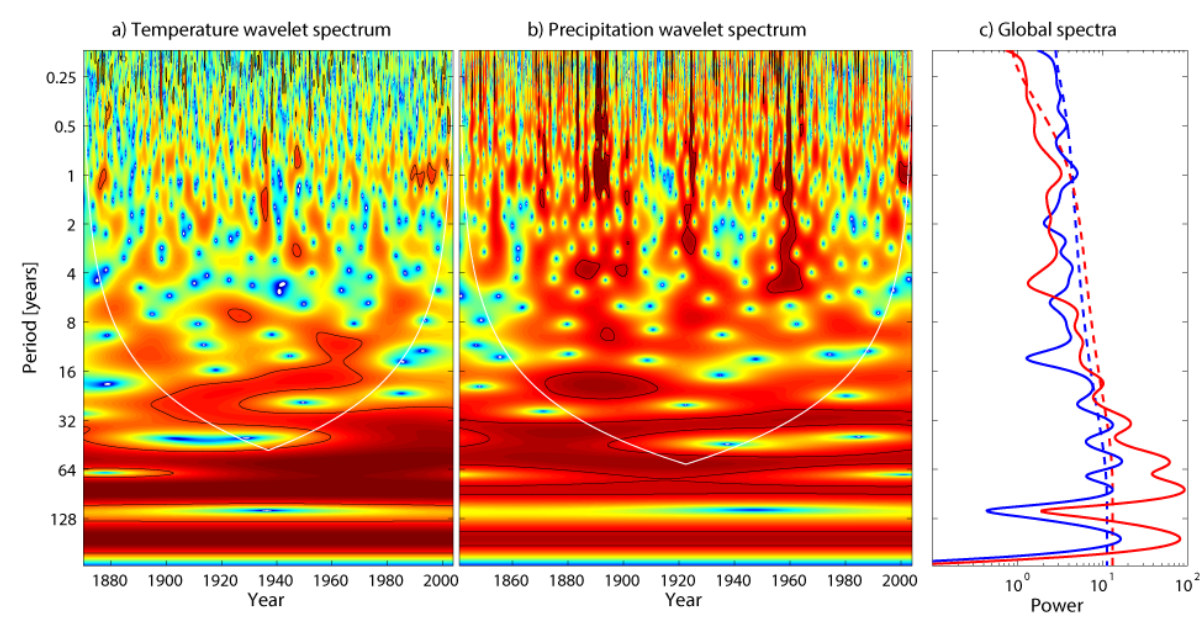

Figure 4. (a) Scalogram of monthly mean temperature anomalies in Beijing. (b) Scalogram of monthly mean precipitation anomalies in Beijing. In panels (a) and (b), thin black lines enclose areas with power above the $5 \%$ significance level. The white cup-shaped curve is the cone of influence (see text). (c) Global wavelet spectra of temperature anomalies (red line) and precipitation anomalies (blue line) and corresponding $5 \%$ significance levels (dashed red and blue lines). In panel (c), quantities related to precipitation are divided by $10^{3}$ for convenience of presentation.

scalograms enclose regions which exhibit significant power at the $95 \%$ c.l. The cup-shaped white line in both scalogram panels represents the cone of influence: power outside the curve is reduced with respect to the hypothetical "true" value, due to zero padding of data performed while computing CWT in the frequency domain (Torrence and Compo, 1998). Figure 4c shows the global wavelet spectra (hereafter GWS) of the two variables, i.e., the time average of scalogram values at each Fourier period. GWS is comparable to a standard power spectrum, but considerably smoothed, particularly at small periods, where the wavelet is narrow in time and broadband in frequency. Statistical tests for scalogram and GWS values were performed according to the guidelines given in Torrence and Compo (1998), with significance levels of $10,5,2$ and $1 \%$ and the assumption of a background spectrum of red noise. In Fig. 4, to avoid clutter, we only show the results of the $5 \%$ significance test. Red lines in Fig. 4 represent temperature; blue lines represent precipitation. Significance levels are drawn as dashed red and blue lines for each of the two.

CWT is a multiresolution analysis, with high-frequency resolution and low time resolution at low frequency, and vice versa. So, in the highest range of periods showing significant GWS power, that is, for periods $>50$ years, the relatively poor time resolution leads to little or no information on the temporal evolution of the significant modes. On the other hand, at the high-frequency end of the spectrum, the frequency resolution of CWT is too poor to allow us to determine the period of interannual oscillations precisely.

For temperature (Fig. 4a and c), the power at high frequency (i.e. in periods $<10$ years) is concentrated in short intervals: time resolution is at a maximum here. High power in periods of 10-12 years is present around 1960, but this contribution is not sufficient to give a significant peak in the GWS. The diffused high power in the 16-32 years range of periods is at a maximum in the interval 1890-1930; then this mode seems to bifurcate into two separate modes, with periods of $\sim 16$ and 30-35 years, but the first mode disappears after 1970. This diffused power produces two separate 20- and 35 -year peaks in the GWS. Diffused high power in longer periods gives a 58-year peak and a 85-year peak in the GWS, as well as a peak in over-centennial periods. Thus, in the global spectrum of temperature we recognize a long-term trend and $85-, 58$ - and 35-year oscillations that are significant at $99 \%$ c.l., plus a 20 -year oscillation which is significant at $95 \%$ c.l.

For precipitation (Fig. $4 b$ and c), the power at high frequency (i.e. in periods smaller than 10 years) is again concentrated in short intervals. High power in periods of 1012 years is present in the interval 1890-1990, but, as in the case of temperature, this contribution is not enough to give a significant peak in the GWS. The power in the 16-20-year range of periods is particularly high in the interval 18701910 and, correspondingly, a 20-year peak appears in the GWS. Diffused high power in the 32-64-year range of periods is visible until $\sim 1900$; then this mode seems to bifurcate into two separate modes, with periods of about 30 and 50-60 years, that last until the end of the record. This feature corresponds to a 58-year peak and a 35-year peak in the GWS. Diffused high power in periods greater than 64 years produces a 85-year peak in the GWS, as well as a peak in over-centennial periods.

The global spectrum of precipitation thus shows the same periodicities found for temperature: the long-term trend, the 58-year and the 35-year oscillations are significant at $99 \%$ c.l., whereas the 85 -year and the 20 -year oscillations are significant at $95 \%$ c.l., though the 20 -year one hardly 
attains this level. The surprising degree to which the two spectra have coincident peaks is evident in Fig. 4c. The spectral behaviors are nearly identical in the low-frequency range; in particular, both spectra have a deep minimum at 115 years, followed by power related to oscillations with periods greater than a century representing the long-term trend of the series.

The analysis of the individual series of mean temperature in each of the four seasons (figures not shown) demonstrated that the 20-year cycle is typical of JJA temperature, i.e., of the summer monsoon season, while the 35-year cycle is most evident in winter. The cycles of $\sim 60$ years and longer periods are present in all four seasons. Obviously, the spectral characteristics of monthly precipitation anomalies are determined by the summer season.

Incidentally, we may also mention the spectral content of the Beijing series in the multiannual range. Due to the CWT poor-frequency resolution at small periods, the position of spectral peaks in this high-frequency band is better studied by stationary spectral methods, such as Fourier methods and the Yule-Walker AR method. Stationary spectra of temperature anomalies (not shown) gave, in the multiannual range, relatively high power in the ranges of 2-4 years and 6-8 years, the typical ENSO periodicities, as well as around 11 years, the length of the solar Schwabe cycle. In the multidecadal range, stationary methods allowed us to detect oscillations of periods of around 20, 35 and 65 years: the wavelet method, due to its high-frequency resolution at low frequencies, is able to resolve, as we have seen, the 65-year peak present in Fourier and AR spectra into two separate maxima of 58 and 85 years. Stationary spectra of precipitation anomalies (not shown) also showed important peaks in the typical ENSO range, 2-8 years, and at the solar 11-year period. In the multidecadal range, as for temperature, the dominant cycles have periods of $\sim 65,35$ and 20 years.

By ICWT, according to the method by Torrence and Compo (1998), it is possible to reconstruct the oscillations corresponding to significant peaks in the GWS: the CWT coefficients corresponding to those Fourier periods (scales) that contribute to the considered peak at all instants are inserted into the ICWT algorithm. This procedure has a certain degree of subjectivity, since the precise interval of Fourier periods to be included is arbitrary. In the present work, oscillations were reconstructed including the contributions of all periods forming the whole spectral peak considered. For both variables, the long-term trend was thus reconstructed including all periods $>115$ years, the 85 -year oscillation was reconstructed including periods from 70 to 115 years, the $\sim 60$ year one including periods from 42 to 70 years, the 35 -year one including periods from 25 to 42 years and the 20 -year one including periods from 17 to 25 years. Therefore, the "multidecadal and centennial" reconstructions, already mentioned, of temperature and precipitation monthly anomalies (Fig. 1) are actually the result of wavelet lowpass filtering with cutoff at a frequency of 17 years $^{-1}$. This is also the reason why, when applying the Mann smoothing filter, the same
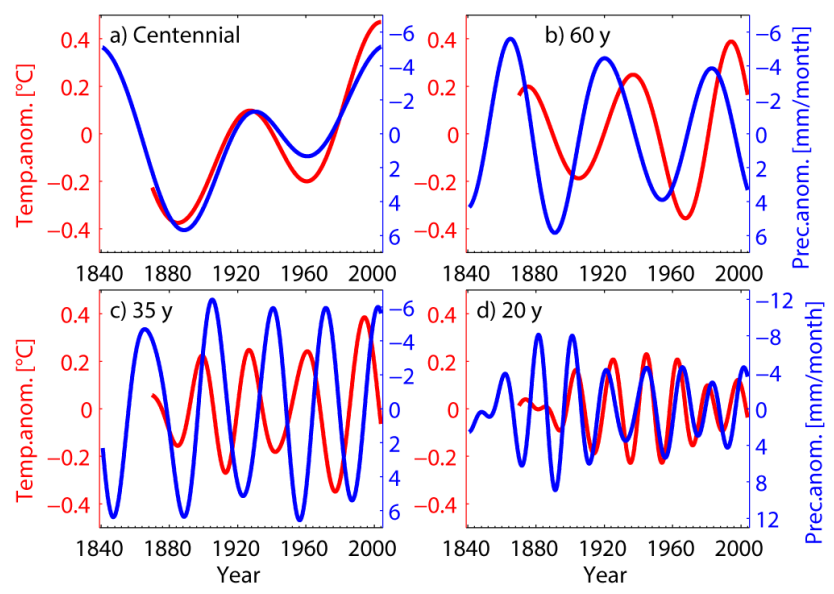

Figure 5. CWT-reconstructed variations of temperature (red lines) and precipitation (blue lines) on different timescales: (a) centennial variations (sum of the trend and the 85-year oscillation), (b) $\sim 60$ year oscillations, (c) $\sim 35$-year oscillations, (d) $\sim 20$-year oscillations. Precipitation axes are reversed.

cutoff was chosen. We now compare (Fig. 5) the individual oscillatory modes extracted in this way from monthly temperature and precipitation anomalies.

In Fig. 5, the precipitation axis is reversed in all panels, in agreement with the general anticorrelation observed in Beijing between temperature and rainfall. This anticorrelation is particularly evident on centennial scales, as shown in panel (a) of Fig. 5. This figure shows the reconstruction on the basis of all periods greater than 70 years, including the long-term trend and the 85-year oscillation. Also on a bidecadal scale (panel d) we find a phase opposition between temperature and precipitation, that however is only approximate and exists only after $\sim 1900$, when the amplitudes of the oscillations in both variables become comparable. We see that amplitude modulation of a given oscillation is related to evolutionary spectral features visible in the corresponding scalogram: for example, precipitation has high spectral power in the interval 1870-1920 around a period of 20 years (Fig. 4a), and, correspondingly, the 20 -year precipitation oscillation (blue line in Fig. 5d) has maximum amplitude in that interval.

Studies on the variability of summer temperature and rainfall over different sectors of East China, based on both observations and general circulation models simulations (Liang et al., 1995), have shown that the correlation between temperature and precipitation may be positive, negative or nonexistent, depending on the varying dynamics of the EASM. When this correlation is negative, as observed in the present study in Beijing, the combined effects of cool air advection from the ocean and increased cloudiness in the summer monsoon season that dominates precipitation, leading to decreased insolation, have been invoked to explain it (Liang et al., 1995). 
The results of CWT analysis were confirmed by application of SSA (Ghil and Vautard, 1991; Vautard et al., 1992; Dettinger et al., 1995; Allen and Smith, 1996; Ghil and Taricco, 1997; Ghil et al., 2002). The SSA technique was designed to extract information from short and relatively noisy time series, such as climatic ones. It provides dataadaptive filters that separate the time series into components that are statistically independent and can be classified as oscillatory patterns and noise. The oscillations can be amplitude and phase modulated (Allen and Smith, 1996). Significant variability components may then be reconstructed as described above (Ghil and Vautard, 1991; Ghil and Taricco, 1997; Ghil et al., 2002). SSA has been applied in the past to many instrumental and proxy climate records (e.g., Ghil and Vautard, 1991; Plaut et al., 1995; Taricco et al., 2009; two review papers (Ghil and Taricco, 1997; Ghil et al., 2002) and references therein cover both methodology and other applications). For the calculations we used the freeware SSAMTM Toolkit (Vautard et al., 1992; Dettinger et al., 1995) available at http://www.atmos.ucla.edu/tcd/ssa/. The SSA reconstructed oscillations, obtained adopting a window length $M=600$, corresponding to 50 years, were found to be consistent with the corresponding ones reconstructed by CWT. As an example, in Fig. 1a the multidecadal and centennial SSA-based reconstruction of temperature, significant at the $99 \%$ c.l., is shown by a grey line and is clearly in agreement with the CWT-based reconstruction (black line).

\section{Comparison with indices of large-scale climatic variability}

\subsection{Comparison with the EASM index}

Li and Zeng $(2002,2003)$ introduced an EASM index that covers the second half of the 20th century, based on the seasonality of the wind field on the area $10-40^{\circ} \mathrm{N}, 110-140^{\circ} \mathrm{E}$. In Fig. 6a, this EASM index (green bars in arbitrary units) is plotted together with Beijing temperature anomalies (thin red line) and with the centennial oscillation extracted by CWT (heavy red line; sum of the trend and of the 85-year oscillation). On a qualitative level, we see that the temperature anomalies are positive when the EASM index is prevalently negative (post 1980) and vice versa. In Fig. 6b, the analogous comparison for precipitation (blue lines) shows precipitation anomalies to be positive when the EASM index is prevalently positive (ante 1970).

The years 1970-1980 thus mark the transition from prevalently strong EASM, characterized by negative temperature anomalies and positive precipitation anomalies in Beijing, and vice versa. Qian et al. (2003) attribute this change from wet to dry - that they date to around 1976 for NC - to a change in the pattern of monsoon circulation over East China. Examining the $850 \mathrm{hPa}$ summer winds over the area, they found that in the summers from 1954 to 1976 there were on average strong south-southwesterly winds that reached North and Northeast China; the summer monsoon was strong and rainfall was concentrated in NC. By contrast, in the summers of 1977-1999, very weak southerly winds were found in East Asia and only reached the South of the lower YR region. This circulation change coincides with a transition in the summer thermal contrast between the inland Asian surface and the surrounding ocean, a contrast that underwent a weakening in the last decades of the 20th century: in particular, a warming was observed over the SCS and the Northwestern Pacific ocean and a relative cooling was observed in central and south China, associated with increased rainfall in these regions (Xu et al., 2006). This transition coincides with the well-known shift that occurred in the mid-1970s, when the tropical Pacific sea surface temperatures (SSTs) passed from a relatively cool state to relatively warm conditions (e.g., Trenberth and Hurrell, 1994). Chao et al. (2000) observed that this shift is not unique and only represents the most evident of several phase shifts, associated with quasibidecadal and possibly quasi-centennial Pacific SST oscillations.

We may note here that even if a generalized relationship between summer and winter monsoons is virtually nonexistent (see, e.g., Wu and Chan, 2005), not only the summer monsoon but also the winter monsoon winds decreased in the last decades of 1900, due to the weakening of the land-ocean winter gradient, related to the stronger warming observed in $\mathrm{NC}$ than over the southern oceans, especially in winter $\mathrm{Xu}$ et al., 2006). A weaker winter monsoon means, in turn, less advection of cold air from the Siberian and Mongolian plateaus in winter, contributing to the remarkable winter temperature increase observed in Beijing.

\subsection{Comparison with multidecadal modes of climatic internal variability: the PDO and the Atlantic Multidecadal Oscillation (AMO)}

Next, we investigate the possible connection between the climate of Northeast China and large-scale climatic variability. To this end, among the indexes of general atmospheric circulation and ocean thermodynamics, we selected two that represent internal modes of variability on multidecadal scales relevant to the dynamics of East-Asian climate: the PDO (Zhang et al., 1997; Mantua et al., 1997) and the AMO (Kerr, 2000) indexes. The standardized values for the PDO index are derived as the leading principal component of monthly SST anomalies in the North Pacific Ocean, poleward of $20^{\circ} \mathrm{N}$. The monthly mean global average SST anomalies are removed to separate this pattern of variability from any "global warming" signal that may be contained in the data. The index series is available from 1900 to the present on a monthly basis. The values of the AMO index are calculated from the SST field over the North Atlantic $\left(0-70^{\circ} \mathrm{N}\right)$, taking the area-weighted SST average and then detrending the 


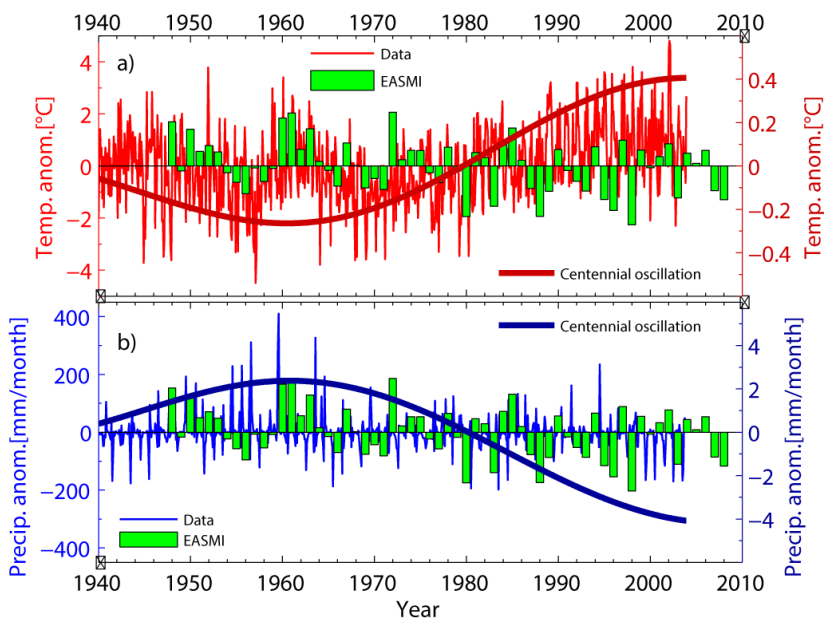

Figure 6. (a) Beijing temperature (left axis, red line) and (b) precipitation (left axis, blue line) anomalies and corresponding centennial oscillations (right axes, dark red and dark blue lines, respectively; sum of trend and 85-year oscillation) compared for the second half of the 20th century with the EASM index by Li and Zeng (2002, 2003), plotted by green bars in arbitrary units. For presentation purposes, the data and the centennial variations in this figure are centered over the interval covered by the EASM index, i.e., the average value computed over 1948-2004 was subtracted from each of them. Centennial oscillations in the two variables are plotted from data on separate axes in order to make their variation clearly visible.

series (Enfield et al., 2001). The index is available from 1856 to the present on a monthly basis.

Figure 7 shows the spectral comparison between Beijing climatic variables and the PDO and AMO indexes. In the PDO index, we detected cycles of $85,57,25,9.2$ and 5.6 years by CWT. In periods longer than $50-60$ years, the GWS of Beijing temperature and precipitation and the GWS of the PDO turn out to be similar (Fig. 7a and b), while PDO shows a single spectral peak at 25 years instead of two separate cycles of 35 and 20 years. The AMO power is more concentrated in the 50-100-year band and shares the cycles of 85 and 57 years with the PDO and Beijing variables (Fig. 7c and d).

In Figs. 8 and 9 , the sum of the $\sim 60$ - and 85 -year oscillations in Beijing (red and blue lines for temperature and precipitation, respectively) is compared with smoothed versions of the PDO and AMO indexes (that by definition have no long-term trend; green areas). The smoothed indexes were obtained by CWT filtering with cutoffs at $1 / 15$ and $1 / 17$ years $^{-1}$, respectively (values suggested by the shape of their respective GWS).

We observe (Fig. 8) that a negative PDO phase prevalently corresponds to relatively cool conditions (panel a) and high precipitation (panel b) in Beijing, and vice versa. It is known that PDO has a significant impact on the climate of the Pacific and China (Cane et al., 1986; Hoerling and Kumar, 2003; McCabe et al., 2004) and in particular that the cooling of
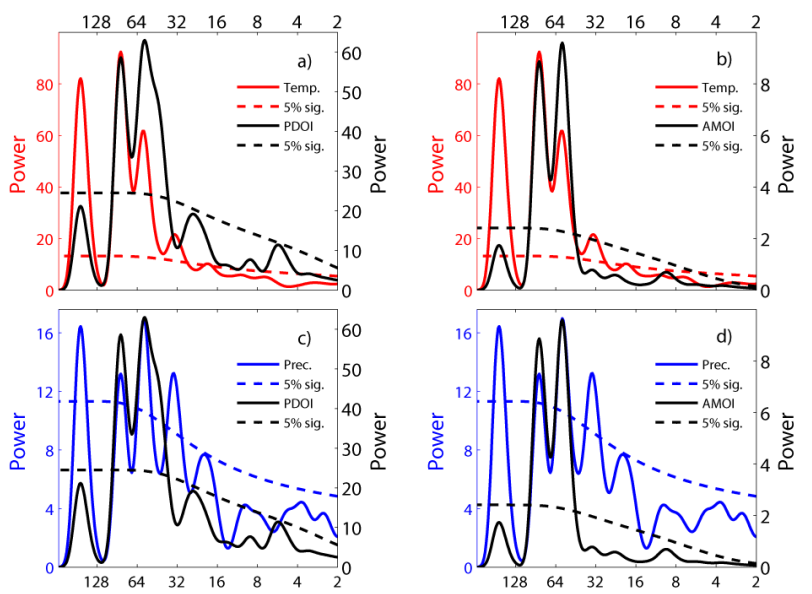

Figure 7. Global wavelet spectra of temperature (panels $\mathbf{a}$ and $\mathbf{b}$, red lines) and precipitation (panels $\mathbf{c}$ and $\mathbf{d}$, blue lines) anomalies in Beijing compared with those of the PDO (panels a and $\mathbf{c}$, black lines) and AMO (panels $\mathbf{b}$ and $\mathbf{d}$, black lines) indexes (PDOI and AMOI, respectively). Dashed lines represent $5 \%$ significance levels. Quantities related to precipitation are divided by $10^{3}$ for convenience of presentation.

the tropical Pacific, associated with the negative phase of the PDO, causes a strengthening of the summer thermal contrast between land and sea, thus reinforcing the EASM, and vice versa (see, e.g., Liu et al., 2008). Wei et al. (2008), accordingly, found a negative correlation at a high confidence level between the PDO index and Beijing precipitation. More recently, Yu (2013) found a correlation between the positive PDO phase and the "Southern flood and Northern drought" summer rainfall pattern over East China. This is in agreement with our findings, which also add information about related temperature variations.

Increased rainfall in Beijing (Fig. 9b) roughly corresponds to positive AMO, also associated with cool conditions (Fig. 9a). The same figure suggests a decadal delay of Beijing's climate response to changing AMO phases. Our result supports the existence of a teleconnection between the North Atlantic climate and EASM, as already proposed by other authors (see, e.g., Lu et al., 2006). The positive phase of the AMO is associated with positive temperature anomalies over Eurasia (Goswami et al., 2006), bringing about a reinforcement of the land-sea summer temperature gradient and therefore of the EASM. The fact that, in turn, a cooling of the North Atlantic is associated with a weakening of the EASM, also through an increase of the Euro-Asiatic snow cover and the subsequent lower continental spring heating, is indicated by paleoclimatic evidence (Fleitmann et al., 2007).

\section{Conclusions}

Two historical time series of monthly temperature and precipitation anomalies in Northeast China (Beijing; Fig. 1) were studied. The variations of temperature in Beijing during 


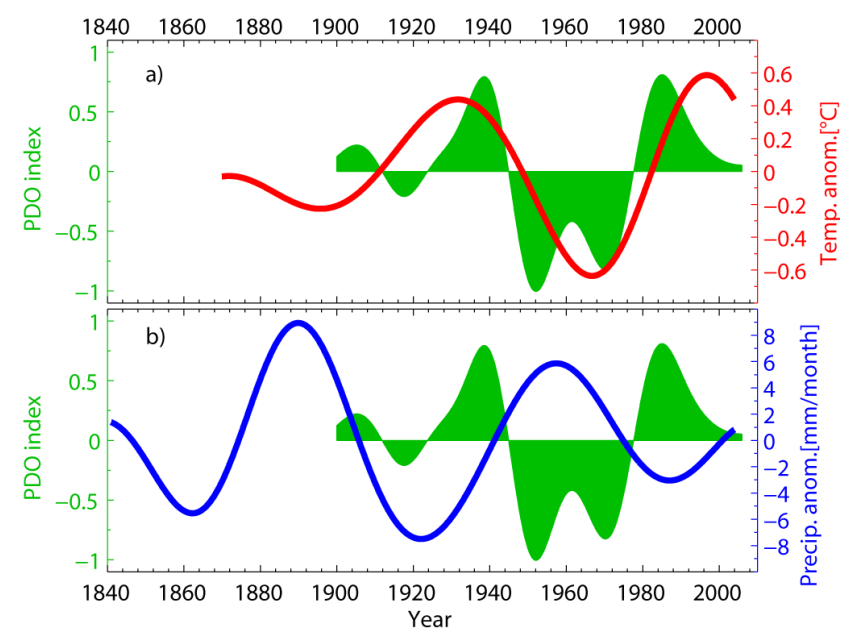

Figure 8. Comparison between the PDO index (smoothed; green areas) and the sum of the 58- and 85-year CWT oscillations of temperature (panel a, red line) and precipitation (panel b, blue line). The smoothing of the PDO index is obtained by CWT filtering with a cutoff at $1 / 15$ years $^{-1}$.

the last century and a half were compared with those shown by two paleoclimatological records from East China (Fig. 2) and with NH temperature anomalies. The modern steep temperature rise in Beijing was shown to have occurred nearly contemporaneously with the hemispheric one (Fig. 3). Significant modes of variability on multidecadal scales were detected in the two series. The spectral content of the two climatic variables turned out to be very similar, so that temperature and precipitation share common periodicities at about $85,60,35$ and 20 years, as well as an over-centennial component representing the long-term trend of each series (Fig. 4). Temperature and precipitation in Beijing show a general anticorrelation. The phase opposition is particularly evident on centennial and on bidecadal scales (Fig. 5). The analysis of the four temperature series relative to single seasons showed that the 20-year cycle is typical of the summer monsoon season, while the 35 -year cycle is most evident in the winter series. The cycles of $\sim 60$ years and longer are present in all seasons. Thanks to the high resolutions characterizing CWT at low frequency and to the availability of monthly records, it was possible - in spite of the short time interval covered by the two historical series - to resolve two multidecadal components of about 60 and 85 years that in previous studies (e.g., Qian et al., 2008; Wei et al., 2008; Zhao et al., 2004; Zhao and Han, 2005) appeared as a single mode with a period of around 70 years.

The centennial variation of temperature and precipitation proved to describe well (Fig. 6) the 1970-1980 transition between a period of relatively strong East Asian Summer Monsoon (EASM), corresponding to high precipitation and relatively cool temperatures in Beijing, and conditions of weak EASM, corresponding to low precipitation and warm temperatures in Beijing.

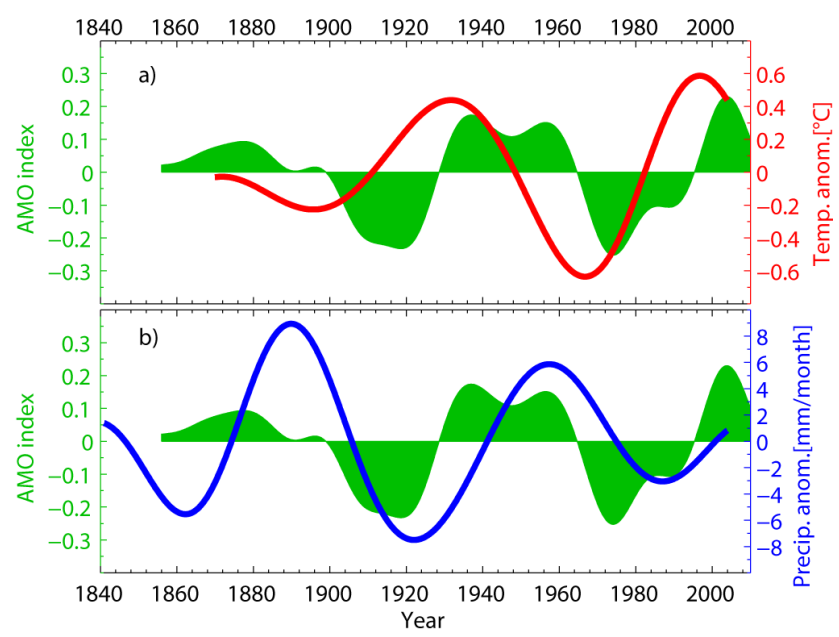

Figure 9. Comparison between the AMO index (smoothed; green areas) and the sum of the 58- and 85-year CWT oscillations of temperature (panel a, red line) and precipitation (panel $\mathbf{b}$, blue line). The smoothing of the AMO index is obtained by CWT filtering with a cutoff at $1 / 17$ years $^{-1}$.

The climatic oscillations detected locally in Beijing probably have a large-scale character, as supported by their comparison with the NH annual mean temperature anomaly HadCRUT3 record and with modes of climate internal variability at multidecadal scale, such as the PDO and AMO.

Acknowledgements. The authors acknowledge Arnaldo Longhetto for establishing the contacts with the Institute of Atmospheric Physics-IAP of the Chinese Academy of Sciences-CAS, Beijing, China, and for his valuable suggestions. The authors also acknowledge Zeng Q. C. (IAP) for kindly providing the data analyzed in this paper; the UK Meteorological Office, Hadley Centre (www.metoffice.gov.uk/hadobs), for making the HadCRUT3 data set available; Nate Mantua of the University of Washington and JISAO-Joint Institute for the Study of the Atmosphere and Ocean for making the PDO index series available at http: //jisao.washington.edu/pdo/PDO.latest; the NOAA-ESRL for the AMO index series, downloadable from http://www.esrl.noaa.gov/ psd/data/timeseries/AMO/; and Jianping Li (State Key Laboratory of Numerical Modeling for Atmospheric Sciences and Geophysical Fluid Dynamics-LASG of IAP-CAS), for the EASM index series, downloadable from http://www.lasg.ac.cn/staff/ljp/data-monsoon/ EASMI.htm. Thanks are due also to C. Torrence and G. P. Compo for providing the free wavelet software (available at http://paos. colorado.edu/research/wavelets/), on which most of the Matlab scripts, used in this work for CWT analysis, are based, and to the authors of the SSA-MTM Toolkit, available at http://www.atmos. ucla.edu/tcd/ssa/.

Topical Editor V. Kotroni thanks two anonymous referees for their help in evaluating this paper. 


\section{References}

Allen, M. R. and Smith, L. A.: Monte Carlo SSA: detecting oscillations in the presence of coloured noise, J. Climate, 9, 3373-3404, 1996.

Bradley, R. S., Diaz, H. F., Jones, P. H., and Kelly, P. M.: Secular Fluctuations of Temperature over Northern Hemisphere Land Areas and Mainland China since the Mid-19th Century, in: The Climate of China and Global Climate, Proceedings of the Beijing International Symposium on Climate, edited by: Ye, D. Z., Fu, C. B., Chao, J. P., and Joshin, M., China Ocean Press, Beijing and Springer-Verlag, Berlin, 1984.

Brohan, P., Kennedy, J. J., Harris, I., Tett, S. F. B., and Jones, P. D.: Uncertainty estimates in regional and global observed temperature changes: a new dataset from 1850, J. Geophys. Res., 111, D12106, doi:10.1029/2005JD006548, 2006.

Cane, M. A., Zebiak, S. E., and Dolan, S. C.: Experimental forecasts of El Niño, Nature, 321, 827-832, doi:10.1038/321827a0, 1986.

Chao, Y., Ghil, M., and McWilliams, J. C.: Pacific Interdecadal variability in This Century's Sea Surface Temperatures, Geophys. Res. Lett., 27, 2261-2264, doi:10.1029/1999GL011324, 2000.

Dettinger, M. D., Ghil, M., Strong, C. M., Weibel, W., and Yiou, P.: Software expedites singular-spectrum analysis of noisy time series, EOS T. Am. Geophys. Un., 76, 12-21, 1995.

Ding, Y. H.: The variability of the Asian Summer Monsoon, J. Meteorol. Soc. Jpn., 85, 21-54, 2007.

Ding, Y. H. and Chan, J. C. L.: The East Asian summer monsoon: an overview, Meteorol. Atmos. Phys., 89, 117-142, 2005.

Enfield, D. B., Mestas-Nunez, A. M., and Trimble, P. J.: The Atlantic Multidecadal Oscillation and its relationship to rainfall and river flows in the continental U.S., Geophys. Res. Lett., 28, 2077-2080, 2001.

Fleitmann, D., Burns, S. J., Mangini, A., Mudelsee, M., Kramers, J., Villa, I., Neff, U., Al-Subbary, A. A., Buettner, A., Hippler, D., and Matter, A.: Holocene ITCZ and Indian monsoon dynamics recorded in stalagmites from Oman and Yemen (Socotra), Quaternary Sci. Rev., 26, 170-188, 2007.

Foufoula-Georgiou, E. and Kumar, P. (Eds.): Wavelets in Geophysics, Academic Press, San Diego, California, 1994.

Ge, Q. S., Zheng, J. Y., Fang, X. Q., Man, Z. M., Zhang, X. Q., Zhang, P. Y., and Wang, W. C.: Winter half-year temperature reconstruction for the middle and lower reaches of the Yellow River and Yangtze River, China, during the past 2000 years, Holocene, 13, 933-940, 2003.

Ge, Q. S., Zheng, J. Y., Hao, Z. X., Zhang, P. Y., and Wang, W. C.: Reconstruction of Historical Climate in China: High-Resolution Precipitation Data from Qing Dynasty Archives, B. Am. Meteorol. Soc., 86, 671-679, 2005.

Ghil, M. and Taricco, C.: Advanced spectral analysis methods, in: Past and Present Variability of the Solar-terrestrial System: Measurement, Data Analysis and Theoretical Models, edited by: Cini Castagnoli, G. and Provenzale, A., IOS Press, Amsterdam, The Netherlands, 137-159, 1997.

Ghil, M. and Vautard, R.: Inter-decadal oscillations and the warming trend in global temperature time series, Nature, 350, 324 327, 1991

Ghil, M., Allen, M. R., Dettinger, M. D., Ide, K., Kondrashov, D., Mann, M. E., Robertson, A. W., Saunders, A., Tian, Y., Varadi, F., and Yiou, P.: Advanced spectral methods for climatic time series, Rev. Geophys., 40, 1.1-1.41, 2002.
Goswami, B. N., Madhusoodanan, M. S., Neema, C. P., and Sengupta, D.: A physical mechanism for North Atlantic SST influence on the Indian summer monsoon, Geophys. Res. Lett., 33, L02706, doi:10.1029/2005GL024803, 2006.

Hao, Z. X., Zheng, J. Y., and Ge, Q. S.: Precipitation cycles in the middle and lower reaches of the Yellow River (1736-2000), J. Geogr. Sci., 18, 17-25, 2008.

Hoerling, M. and Kumar, A.: The perfect ocean for drought, Science, 299, 691-694, 2003.

Huang, R., Chen, J., Wang, L., and Lin, Z.: Characteristics, processes and causes of the spatio-temporal variabilities of the East Asian Monsoon system, Adv. Atmos. Sci., 29, 910-942, 2012.

Kerr, R. A.: A North Atlantic climate pacemaker for the centuries, Science, 288, 1984-1985, 2000.

Li, J. P. and Zeng, Q. C.: A unified monsoon index, Geophys. Res. Lett., 29, 115.1-115.4, doi:10.1029/2001GL013874, 2002.

Li, J. P. and Zeng, Q. C.: A new monsoon index and the geographical distribution of the global monsoons, Adv. Atmos. Sci., 20, 299-302, 2003.

Liang, X. Z., Samel, A. N., and Wang, W. C.: Observed and GCM simulated decadal variability of monsoon rainfall in east China, Clim. Dynam., 11, 103-114, 1995.

Liu, J. H., Zhang, P. Z., Cheng, H., Chen, F. H., Yang, X. L., Zhang, D. Z., Zhou, J., Jia, J. H., An, C. H., Sang, W. C., and Johnson, K. R.: Asian summer monsoon precipitation recorded by stalagmite oxygen isotopic composition in the western Loess Plateau during AD 1875-2003 and its linkage with ocean-atmosphere system, Chinese Sci. Bull., 53, 2041-2049, 2008.

Lu, R. Y., Dong, B. W., and Ding, H.: Impact of the Atlantic Multidecadal Oscillation on the Asian Summer Monsoon, Geophys. Res. Lett., 33, L24701, doi:10.1029/2006GL027655, 2006.

Mann, M. E.: On smoothing potentially non-stationary climate time series, Geophys. Res. Lett., 31, L07214, doi:10.1029/2004GL019569, 2004.

Mann, M. E.: Smoothing of climate time series revisited, Geophys. Res. Lett., 35, L16708, doi:10.1029/2008GL034716, 2008.

Mann, M. E. and Park, J.: Global-scale modes of surface temperature variability on interannual to century timescales, J. Geophys. Res., 99, 25819-25833, 1994.

Mantua, N. J., Hare, S. R., Zhang, Y., Wallace, J. M., and Francis, R. C.: A Pacific inter-decadal climate oscillation with impacts on salmon production, B. Am. Meteorol. Soc., 78, 1069-1079, 1997.

McCabe, G. J., Palecki, M. A., and Betancourt, J. L.: Pacific and Atlantic ocean influences on multidecadal drought frequency in the United States, P. Natl. Acad. Sci. USA, 101, 4136-4141, 2004.

Percival, D. B. and Walden, A. T.: Wavelet methods for time series analysis, Cambridge University Press, Cambridge, 2000.

Plaut, G., Ghil M., and Vautard, R.: Interannual and interdecadal variability in 335 years of Central England temperatures, Science, 268, 710-713, 1995.

Portman, D. A.: Identifying and correcting urban bias in regional time series: surface temperature in China's Northern Plains, J. Climate, 6, 2298-2308, 1993.

Qian, W. H., Hu, Q., Zhu, Y. F., and Lee, D. K.: Centennial-scale dry-wet variations in East Asia, Clim. Dynam., 21, 77-89, 2003.

Qian, W. H., Ding, T., Fu, J. L., Lin, X., and Zhu, Y. F.: Review on the Data Application and Climate Variability in China for Various Timescales, Adv. Clim. Chang. Res., 4, 1-6, 2008. 
Schlesinger, M. E. and Ramankutty, N.: An oscillation in the global climate system of period 65-70 years, Nature, 367, 723-726, 1994.

Shen, C., Wang, W.-C., Peng, Y., Xu, Y., and Zheng, J.: Variability of summer precipitation over Eastern China during the last millennium, Clim. Past, 5, 129-141, doi:10.5194/cp-5-129-2009, 2009.

Solomon, S., Qin, D., Manning, M., Chen, Z., Marquis, M., Averyt, K. B., Tignor, M., and Miller, H. L. (Eds.): Climate Change 2007: The Physical Science Basis. Contribution of Working Group I to the Fourth Assessment Report of the Intergovernmental Panel on Climate Change, Cambridge University Press, Cambridge, UK and New York, NY, USA, 2007.

Stige, L. C., Chan, K. F., Zhang, Z. B., Frank, D., and Stenseth, N. C.: Thousand-year-long Chinese time series reveals climatic forcing of decadal locust dynamics, P. Natl. Acad. Sci. USA, 104, 16188-16193, 2007.

Tan, M., Liu, T. S., Hou, J., Qin, X., Zhang, H., and Li, T.: Cyclic rapid warming on centennial-scale revealed by a 2650 -year stalagmite record of warm season temperature, Geophys. Res. Lett., 30, 1617-1620, 2003.

Tao, F., Yokozawa, M., Zhang, Z., Hayashi, Y., Grassl, H., and Fu, C. B.: Variability in climatology and agricultural production in China in association with the East Asian summer monsoon and El Niño Southern Oscillation, Clim. Res., 28, 23-30, 2004.

Taricco, C., Ghil, M., Alessio, S., and Vivaldo, G.: Two millennia of climate variability in the Central Mediterranean, Clim. Past, 5, 171-181, doi:10.5194/cp-5-171-2009, 2009.

Torrence, C. and Compo, G. P.: A Practical Guide to Wavelet Analysis, B. Am. Meteorol. Soc., 79, 61-78, 1998.

Trenberth, K. and Hurrel, J. W.: Decadal Atmosphere-Ocean Variations in the Pacific, Clim. Dynam., 9, 303-319, 1994.

Vautard, R., Yiou, P., and Ghil, M.: Singular-spectrum analysis: A toolkit for short, noisy chaotic signals, Physica D, 58, 95-126, 1992.

Wang, B. and Lin, H.: Rainy season of the Asian-Pacific summer monsoon, J. Climate, 15, 386-396, 2002.

Wang, S. W., Ye, J. L., Gong, D. Y., Zhu, J. H., and Yao, T. D.: Construction of mean annual temperature series for the last one hundred years in China, Q. J. Appl. Meteorol., 9, 392-401, 1998.

Wang, S. W., Gong, D. Y., Ye, J. L., and Chen, Z. H.: Seasonal precipitation series of eastern China since 1880 and the variability, Acta Geograph. Sin., 55, 281-293, 2000.

Wang, S. W., Zhu, J. H., and Cai, J. N.: Inter-decadal variability of temperature and precipitation in China since 1880, Adv. Atmos. Sci., 21, 307-313, 2004.

Wang, S. W., Wen, X. Y., Luo, Y., Dong, W. J., Zhao, Z. C., and Yang, B.: Reconstruction of temperature series of China for the last 1000 years, Chinese Sci. Bull., 52, 3272-3280, 2007.
Wei, F. Y., Xie, Y., and Mann, M. E.: Probabilistic trend of anomalous summer rainfall in Beijing: Role of interdecadal variability, J. Geophys. Res., 113, D20106, doi:10.1029/2008JD010111, 2008.

Wu, M. C. and Chan, J. C. L.: Observational relationships between summer and winter monsoons over East Asia. Part II: Results, Int. J. Climatol., 25, 453-468, 2005.

Xu, M., Chang, C. P., Fu, C., Qi, Y., Robock, A., Robinson, D., and Zhang, H.: Steady decline of east Asian monsoon winds, 19692000: Evidence from direct ground measurements of wind speed, J. Geophys. Res., 111, D24111, doi:10.1029/2006JD007337, 2006.

Yan, Z. W., Li, Z., Li, Q. X., and Jones, P.: Effects of site change and urbanisation in the Beijing temperature series 1977-2006, Int. J. Climatol., 30, 1226-1234, doi:10.1002/joc.1971, 2010.

Yang, B., Bräuning, A., Johnson, K. R., and Shi, Y. F.: General characteristics of temperature variation in China during the last two millennia, Geophys. Res. Lett., 29, 1324, doi:10.1029/2001GL014485, 2002.

Yang, M. X., Yao, T. D., Gou, X. H., Wang, H. J., and Neumann, T.: Wavelet analysis reveals periodic oscillations in a 1700 year ice-core record from Guliya, China, Ann. Glaciol., 43, 132-136, 2006.

Yu, L.: Potential correlation between the decadal East Asian summer monsoon variability and the Pacific decadal oscillation, Atmos. Ocean. Sc. Lett., 6, 394-397, doi:10.3878/j.issn.16742834.13.0040, 2013.

Zhang, Y., Wallace, J. M., and Battisti, D. S.: ENSO-like interdecadal variability: 1900-93, J. Climate, 10, 1004-1020, 1997.

Zhang, Z. B., Cazelles, B., Tian, H. D., Stige, L. C., Bräuning, A., and Stenseth, N. C.: Periodic temperature-associated drought/flood drives locust plagues in China, P. Roy. Soc. B, 276, 823-831, 2009.

Zhao, J. and Han, Y. B.: Determination of precipitation cycle in Beijing area and comparison with solar activity cycle, Earth Moon Planet., 97, 69-78, 2005.

Zhao, J., Han, Y. B., and Li, Z. A.: The Effect of Solar Activity on the Annual Precipitation in the Beijing Area, Chin. J. Astron. Astrophys., 4, 189-197, 2004.

Zhao, P. and Zhou, Z.: An East Asian Subtropical Summer Monsoon Index and its Relationship to Summer Rainfall in China, Acta Meteorol. Sin., 23, 18-28, 2008.

Zheng, J. Y., Hao, X. Z., and Ge, Q. S.: Reconstruction of annual precipitation in the middle and lower reaches of the Yellow River for the last 300 years, Sci. China Ser. D, 35, 765-774, 2005. 